\title{
The New Mission of Forensic Mental Health Systems: Managing Violence as a Medical Syndrome in an Environment that Balances Treatment and Safety - ERRATUM
}

\author{
K. Warburton
}

First published online 27 August 2014

doi:10.1017/S109285291400025X, Published by Cambridge University Press, $17^{\text {th }}$ March, 2014.

There is a typographical error on page three, in the section Addressing substance abuse: "buproprion" should read "bupropion."

The publisher regrets the error.

\section{REFERENCE:}

K. Warburton (2014). The New Mission of Forensic Mental Health Systems: Managing Violence as a Medical Syndrome in an Environment that Balances Treatment and Safety. CNS Spectrums. doi: $10.1017 / \mathrm{S} 109285291400025 \mathrm{X}$ 